\title{
Distinct Associations Between Depression Status and Initial Phase of Gastric Emptying in Functional Dyspepsia and Healthy Volunteers
}

\author{
Mayumi Shimpuku ${ }^{1}$, Seiji Futagami ${ }^{1}$, Masahiko Inamori ${ }^{2}$, Hiroshi Yamawaki ${ }^{1}$, Hitomi Sato ${ }^{1}$, Yasuhiro Kodaka ${ }^{1}$, Hiroyuki \\ Nagoya $^{1}$, Katya Gudis ${ }^{1}$, Tetsuro Kawagoe ${ }^{1}$, Fumihito Saitow ${ }^{3}$, Hidenori Suzuki ${ }^{3}$ and Choitsu Sakamoto ${ }^{1}$ \\ ${ }^{1}$ Department of Gastroenterology, Nippon Medical School, Graduate School of Medicine, 1-1-5 Sendagi, Bunkyo-ku, Japan \\ ${ }^{2}$ Gastroenterology Division, Yokohama City University Hospital, Yokohama, 236-0004, Japan \\ ${ }^{3}$ Department of Pharmacology, Nippon Medical School, Graduate School of Medicine, 1-1-5 Sendagi, Bunkyo-ku, Japan
}

Abstract
Background/Aims: The association between initial phase of gastric emptying and clinical symptoms and
depression status in functional dyspepsia has not been studied in detail.
Methods: The subjects were 20 patients with Rome III-based functional dyspepsia and healthy volunteers.
We evaluated upper abdominal symptoms using GDSS score and used Self-Rating Questionnaire for
Depression (SRQ-D) scores to determine depression status. Gastric motility was evaluated with the
${ }^{13}$ C-acetate breath test.
Results: $\mathrm{AUC}_{15}$ value as initial gastric emptying within 15 mins in FD patients was significantly higher
compared to that in healthy volunteers. $\mathrm{T}_{\text {max }}$ value as a marker of delayed gastric emptying in FD
patients was also significantly higher compared to that in healthy volunteers. There were not significant
relationships between clinical symptoms and $\mathrm{AUC}_{5}$ and $\mathrm{AUC} \mathrm{C}_{15}$ values in FD patients and healthy
volunteers. In contrast, there were significant correlations (p=0.047, p=0.049) between SRQ-D score
and AUC ${ }_{5}$ and AUC $\mathrm{C}_{15}$ values in healthy volunteers, albeit there were not significant correlations in FD
patients.
Conclusions: Impairment of $\mathrm{AUC}_{15}$ or AUC $\mathrm{A}_{15} / \mathrm{AUC}_{\text {inf }}$ as well as delayed gastric emptying would play
important roles in functional dyspepsia. Further studies are necessary to clarify whether various clinical
symptoms and depression status are related to initial gastric emptying at postprandial 15 mins phase.

\section{Publication History:}

Received: July 04, 2014

Accepted: September 24, 2014

Published: September 26, 201

\section{Keywords:}

Functional dyspepsia, Initial phase of gastric emptying, AUC value, SRQ-D

\section{Background}

Functional dyspepsia (FD) has been subclassified into two new disease categories under the Rome III classification criteria: epigastric pain syndrome (EPS) and postprandial distress syndrome (PDS) [1]. Most of FD patients complain various symptoms related to the intake of meals; however, the athophysiology of FD remains poorly defined $[2,3]$ A number of potentially important abnormalities have been reported in FD patients, including impaired fundic accommodation [4], gastric hypersensitivity to distention [5], abonormal duodenojejunal motility [6], duodenal motor and sensory dysfunction [7], duodenal hypersensitivity [8], hereditary factors $[9,10]$, Helicobacter pylori infection [11] and other infections. Impairment of gastric motility such as gastric emptying is strongly associated with the pathophysiology of $\mathrm{FD}$, one of the most common gastrointestinal disorders [12]. In addition, several studies have reported that gastric motility was also associated with psychogenic factors in FD patient's $[13,14]$. We have previously reported that $\mathrm{T}_{\max }$ value as a marker of gastric emptying in PDS patients was significantly greater compared with that of healthy volunteers [15]. We have reported that prokinetics like mosapride citrate improves clinical symptoms by affecting the $\mathrm{T}_{\max }$ value in proton pump inhibitor (PPI)-resistant NERD patients with impaired gastric emptying [16]. In addition, we have also reported that nizatidine administration significantly improved both gastric emptying and clinical symptoms in FD patients with impaired gastric emptying [17]. Therefore, we have considered that $\mathrm{T}_{\max }$ value using ${ }^{13} \mathrm{C}$-acetate breath test were the useful marker for treatment of $\mathrm{FD}$ patients.

In contrast, previous studies have reported that delayed gastric emptying was about $30 \%$ of the patients with FD [18-20]. In addition, Kusano et al have reported that rapid gastric emptying might be a more important factor than delayed gastric emptying in patients with FD [21]. Another study has reported that gastric emptying rate $(\mathrm{ml} / \mathrm{min})$ at $5 \mathrm{~min}$ of the patients with FD was significantly higher compared to healthy volunteers [5]. However, early phase of gastric emptying could not be evaluated by $\mathrm{T}_{\max }$ value or $\mathrm{T}_{1 / 2}$ values. AUC values within $15 \mathrm{mins}$ may be important for consideration for etiology of FD patients through evaluating initial gastric emptying within 15 mins. Therefore, in this study, we aimed to determine to investigate whether $\mathrm{AUC}_{15}$ or $\mathrm{AUC}_{15} / \mathrm{AUC}_{\text {inf }}$ values as initial gastric emptying within 15 mins were also associated with clinical symptoms and and depressive state in FD patients.

\section{Materials and Methods}

\section{Subjects}

Thirty healthy volunteers (Age: 28-52, Sex: M25/F5, BMI: 2.92 \pm 0.59 ), with no clinical history of gastroduodenal disease including symptoms of FD, were recruited. Exclusion criteria included severe heart disease, renal or pulmonary failure, liver cirrhosis, severe systemic illness, history of malignant disease, and erosive GERD. Patients with previous gastroduodenal surgery, duodenal ulcer scars, diabetes mellitus, and recent use of non-steroidal anti-inflammatory drugs, proton pump inhibitors or anticoagulants at endoscopy were also excluded.

"Corresponding Author: Dr. Seiji Futagami, MD, PhD, Department of Gastroenterology, Nippon Medical School, Graduate School of Medicine, 1-1-5 Sendagi, Bunkyo-ku, Japan, E-mail: seiji.futagami@gmail.com

Citation: Shimpuku M, Futagami S, Inamori M, Yamawaki H, Sato H, et al. (2014) Distinct Associations Between Depression Status and Initial Phase of Gastric Emptying in Functional Dyspepsia and Healthy Volunteers. Int J Gastroentero Disord Ther 1: 106. doi: http://dx.doi.org/10.15344/2393-8498/2014/106

Copyright: (c) 2014 Shimpuku et al. This is an open-access article distributed under the terms of the Creative Commons Attribution License, which permits unrestricted use, distribution, and reproduction in any medium, provided the original author and source are credited. 
Citation: Shimpuku M, Futagami S, Inamori M, Yamawaki H, Sato H, et al. (2014) Distinct Associations Between Depression Status and Initial Phase of Gastric Emptying in Functional Dyspepsia and Healthy Volunteers. Int J Gastroenterol Disord Ther 1: 106. DOI: http://dx.doi.org/10.15344/2393-8498/2014/106

Page 2 of 6

Twenty consecutive patients (Age: 35-80, Sex: M3/F17, BMI: $22.34 \pm 0.93$ ) presenting with typical symptoms of FD were enrolled after upper gastrointestinal endoscopy. Patients presented with various types of abdominal symptoms including nausea and upper abdominal discomfort, in addition to the four typical upper abdominal symptoms defined by the Rome III criteria [22]: bothersome postprandial fullness, early satiation, epigastric pain and epigastric burning. Dyspeptic symptoms were defined as pain or discomfort in the upper abdomen for the past three months, with symptom onset at least six months prior to medical check-up. Diagnostic criteria for PDS included bothersome postprandial fullness after ordinary sized meals, and/or early satiation that prevented completion of a normal meal, with either symptom occurring at least several times a week. Diagnostic criteria for EPS included all of the following: pain or burning that is intermittent, localized to the epigastrium, of at least moderate severity, and occurring at least once per week.

Written informed consent was obtained from all subjects prior to upper gastrointestinal endoscopy and abdominal ultrasonography for evaluation of dyspeptic symptoms. The study protocol was approved by the Ethics Review Committee of Nippon Medical School Hospital.

\section{Clinical symptoms}

Clinical symptoms of FD were evaluated according to the Rome III criteria [22]. We assessed abdominal symptoms using the modified Glasgow dyspepsia severity score (GDSS) [9, 17, 23, 24], which is based on frequency (never, score 0 ; on only 1 or 2 days, score 1 ; on approximately 1 day per week, score 3; on approximately $50 \%$ of days, score 4; on most days, score 5), duration (minimun score, 0 ; maximal score 5), and intensity of symptoms (minimun score, 0 ; maximal score, 3). Status of depression was evaluated by Self-Rating Questionnaire for Depression (SRQ-D) scores [25].

\section{Measurement of gastric motility}

Sodium acetate (water-soluble) for emptying of liquids was used as tracer (Cambridge Isotope Laboratories, Cambridge, Mass., USA). The liquid test meal consisted of $100 \mathrm{mg}$ of ${ }^{13} \mathrm{C}$-acetate dissolved in $200 \mathrm{ml}$ of a liquid meal (Racol, $1 \mathrm{ml} / 1 \mathrm{kcal}$; Otsuka Pharmacia Company, Tokyo, Japan). Breath samples were collected 0 and 10s and 5, 10, 15, $20,30,40,50,60,75$ and 90 min after ingestion of the test meal at 10:00 a.m. Patients were instructed not to drink, eat or smoke during the test. Probes were analyzed by non-dispersive infrared spectroscopy (IRIS, Wagner Analyzentechnik, Bremen, Germany). The subject's own production of $300 \mathrm{mmol} \mathrm{CO}_{2}$ per $\mathrm{m}^{2}$ body surface and per hour was set as default. We used an Integrated Software Solutions program to calculate the half gastric emptying time $\left(\mathrm{T}_{1 / 2}\right)$ and the lag phase $\left(\mathrm{T}_{\max } ; \mathrm{min}\right)$ as the point of maximum gastric emptying according to Hellmig et al. [26]. The half gastric emptying time $\left(\mathrm{T}_{1 / 2}\right)$ represents the time when $50 \%$ of the initial gastric content was emptied. A $\mathrm{T}_{\max }$ value of $>65 \mathrm{~min}$, representing the mean $\mathrm{T}_{\max }$ in healthy volunteers plus 2SD, was defined to represent disturbances in gastric emptying according to the diagnostic criteria of the Japan Society of Smooth Muscle Research.

\section{Data Analysis}

The time plot of pulmonary $\left[{ }^{13} \mathrm{CO}_{2}\right]$ excretion (\%dose/hr) was fitted to the function:

$(\%$ dose $/ \mathrm{hr})=\mathrm{m} \times \mathrm{k} \times \beta \times \mathrm{e}^{-\mathrm{kt}} \mathrm{x}\left(1-\mathrm{e}^{-\mathrm{kt}}\right)^{\beta-1}$

where $\mathrm{m}$ is the cumulative $\left[{ }^{13} \mathrm{CO}_{2}\right]$ recovery at the infinite time, $\mathrm{t}$ is in hours and $\mathrm{k}$ and $\beta$ are regression estimated constants.
$($ Cumulative $\%$ dose $)=\mathrm{m} \times\left(1-\mathrm{e}^{-\mathrm{kt}}\right)^{\beta}$

$\mathrm{AUC}_{5} \times \mathrm{mx}\left(1-\mathrm{e}^{-\mathrm{k} \times 0.08}\right)^{\beta}[\mathrm{T}: 5 \mathrm{~min}=0.08 \mathrm{hr}]$

$\mathrm{AUC}_{15} \times \mathrm{mx}\left(1-\mathrm{e}^{-\mathrm{k} \times 0.25}\right)^{\beta}[\mathrm{T}: 15 \mathrm{~min}=0.25 \mathrm{hr}]$

$\mathrm{AUC}_{30} \times \mathrm{mx}\left(1-\mathrm{e}^{-\mathrm{k} \times 0.5}\right)^{\beta}[\mathrm{T}: 30 \mathrm{~min}=0.5 \mathrm{hr}]$

$\mathrm{AUC}_{60} \times \mathrm{mx}\left(1-\mathrm{e}^{-\mathrm{k} \times 1.0}\right)^{\beta}[\mathrm{T}: 60 \mathrm{~min}=1.0 \mathrm{hr}]$

$\mathrm{AUC}_{90} \times \mathrm{mx}\left(1-\mathrm{e}^{-\mathrm{k} \times 1.5}\right)^{\beta}[\mathrm{T}: 90 \mathrm{~min}=1.5 \mathrm{hr}]$

$\mathrm{AUC}_{\text {inf }}\left(\mathrm{AUC}_{\infty}\right) \times \mathrm{mx}\left(1-\mathrm{e}^{-\mathrm{k} \times 24}\right)^{\beta}[\mathrm{T}: 1440 \mathrm{~min}=24 \mathrm{hr}]$

We determined $\mathrm{AUC}_{5}$ and $\mathrm{AUC}_{15}$ values as the marker of early phase of gastric emptying based on previous reports [4,5,27-30]. AUC value $_{5}$ of $>17.4$ and $\mathrm{AUC}_{15}$ value of $>39.6$ representing the mean AUC value of healthy volunteers plus $2 \mathrm{SD}$ was defined to represent disturbance in early phase of gastric emptying.

\section{Sample size}

In our study, we determined the sample size using the PS (Power and Sample size calculations program) software program, a gift from Vanderbilt University. The deviation of the $\mathrm{AUC}_{15}$ value in healthy volunteers was approximately $2.2(\sigma=2.2)$. Using the above data and settings of $\alpha=0.05, \beta=0.80$, effect size $=0.639$ and an estimated mean $\mathrm{AUC}_{15}$ value of 42.507 (\% dose) in patients with $\mathrm{FD}$, thirty healthy volunteers and $20 \mathrm{FD}$ patients were determined to be sufficiency to identify clinically relevant differences.

\section{Statistical analysis}

For the statistical evaluation of group data, Students' t-test for paired data and an analysis of variance (ANOVA) for multiple comparisons were followed by Scheffe's F test. The Mann-Whitney U test was used for the analysis of categorical data. The data analysis were performed using a standard software package (SPSS version 13.0, Chicago, IL). A $\mathrm{p}$ value of $<0.05$ was statistically significant.

\section{Results}

\section{Characteristics of FD patients and healthy volunteers}

Clinical symptoms including nausea, abdominal fullness, abdominal pain, abdominal discomfort and Glasgow score in FD patients were significantly higher compared to healthy volunteers (Figure 1).

\section{Comparison of AUC and $\mathrm{T}_{\max }$ values in FD patients and healthy volunteers}

$\mathrm{T}_{\max }(57.26 \pm 3.9)$ value in FD patients was significantly $(\mathrm{p}=0.002)$ greater compared to that $\left(\mathrm{T}_{\max }: 45.53 \pm 1.43\right)$ in healthy volunteers (Figure 2). To compare $\mathrm{AUC}_{90}$ value with $\mathrm{AUC}$ infinity value $\left(\mathrm{AUC}_{\text {inf }}\right)$, we measured $\mathrm{AUC}_{90} / \mathrm{AUC}_{\text {inf }}$ ratio in $\mathrm{FD}$ patients and healthy volunteers. Since $\mathrm{AUC}_{90} / \mathrm{AUC}_{\text {inf }}$ ratios in $\mathrm{FD}$ patients and healthy volunteers were more than $90 \%(97.52 \pm 0.79,93.61 \pm 2.24$, respectively), we calculated $\mathrm{AUC}_{5}$ and $\mathrm{AUC}_{15}$ values in this study as well as in $4 \mathrm{hr}{ }^{13} \mathrm{C}$-acetate breath test. Interestingly, $\mathrm{AUC}_{5}(18.41 \pm 1.20)$ and $\mathrm{AUC}_{15}(44.17 \pm 2.35)$ values in $\mathrm{FD}$ patients were also significantly $(\mathrm{p}=0.008, \mathrm{p}=0.009)$ greater compared to those $\left(\mathrm{AUC}_{5}: 15.18 \pm 1.09\right.$, $\left.\mathrm{AUC}_{15}: 35.13 \pm 2.22\right)$ in healthy volunteers (Figure 2). Then, there was no significant ( $\mathrm{p}=0.714$ correlation between $\mathrm{T}_{\max }$ value and Glasgow score in FD patients. Subanalysis of Glasgow score showed that there were no significant relationship ( $\mathrm{p}=0.07, \mathrm{p}=0.897, \mathrm{p}=0.591$ ) between $\mathrm{T}_{\max }$ alue and nausea, epigastralgia and abdominal discomfort in FD patients. 
Citation: Shimpuku M, Futagami S, Inamori M, Yamawaki H, Sato H, et al. (2014) Distinct Associations Between Depression Status and Initial Phase of Gastric Emptying in Functional Dyspepsia and Healthy Volunteers. Int J Gastroenterol Disord Ther 1: 106. DOI: http://dx.doi.org/10.15344/2393-8498/2014/106

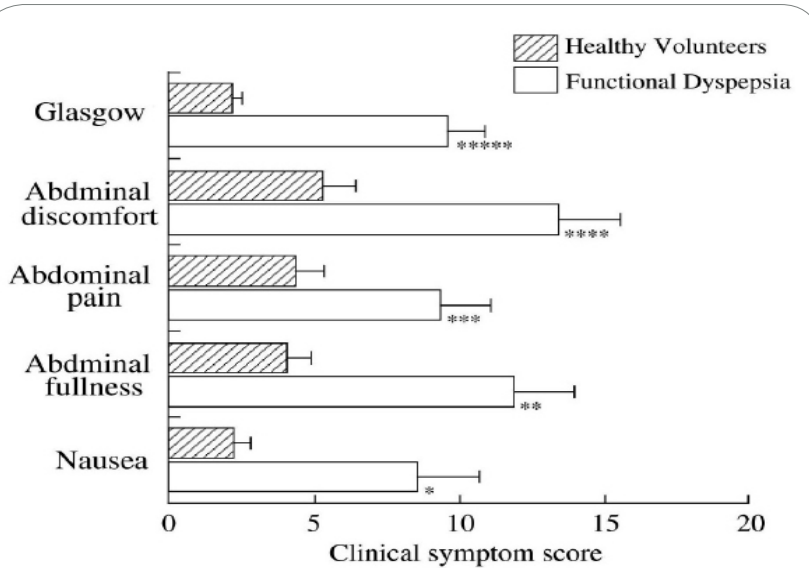

Figure 1: Clinical symptom score in FD patients and healthy volunteers.

Clinical symptoms including nausea, abdominal fullness, abdominal pain, abdominal discomfort and glasgow score in FD patients were significantly higher compared to healthy volunteers. ${ }^{\star}$ vs. healthy volunteers, $\mathrm{p}=0.001{ }^{* *} \mathrm{vs}$. healthy volunteers, $\mathrm{p}<0.001{ }^{* * *} \mathrm{vs}$. healthy volunteers, $\mathrm{p}=0.01{ }^{* * * *} \mathrm{vs}$. healthy volunteers, $\mathrm{p}<0.001 .^{* * * *} \mathrm{vs}$. healthy volunteers, $\mathrm{p}<0.0001$

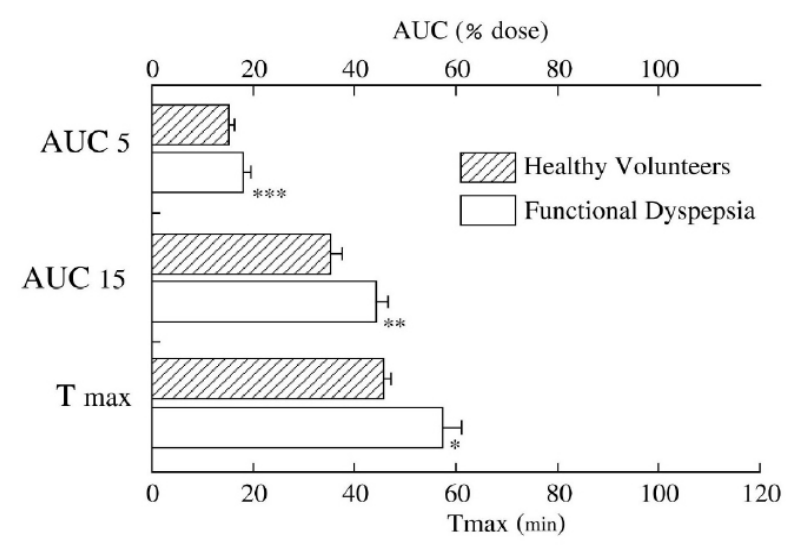

Figure 2: Comparison of $\mathrm{T}_{\max }, \mathrm{AUC}_{5}$ and $\mathrm{AUC}_{15}$ values between FD patients and healthy volunteers.

$\mathrm{T}_{\text {max }}$ (min) value in FD patients was significantly greater compared to those in healthy volunteers. $\mathrm{AUC}_{5}$ (\% dose) and $\mathrm{AUC}_{15}(\%$ dose) values in FD patients were also significantly greater compared to those in healthy volunteers. ${ }^{*} v s$. healthy volunteers, $\mathrm{p}=0.002 ;{ }^{* *} \mathrm{vs}$. healthy volunteers, $\mathrm{p}=0.08 ;{ }^{* *}$ vs. healthy volunteers, $\mathrm{p}=0.009$.

\section{Correlation between clinical symptoms and AUC values in FD patients}

There were no significant relationship $(\mathrm{p}=0.230 ; \mathrm{p}=0.259)$ between $\mathrm{AUC}_{5}$ and $\mathrm{AUC}_{15}$ values and Glasgow score in $\mathrm{FD}$ patients. In addition, in this study, to investigate the relationship between initial gastric emptying within 15 mins and abdominal fullness after meals, we compared $\mathrm{AUC}_{5}, \mathrm{AUC}_{15}, \mathrm{AUC}_{5} / \mathrm{AUC}_{\mathrm{inf}}$ and $\mathrm{AUC}_{15} / \mathrm{AUC}_{\text {inf }}$ values with abdominal fullness. There is no significant correlation ( $\mathrm{p}=0.472, \mathrm{R}^{2}=0.0186 ; \mathrm{p}=0.704, \mathrm{R}^{2}=0.005$ ) between abdominal fullness and $\mathrm{AUC}_{5}$ and $\mathrm{AUC}_{15}$ values in healthy volunteers (Figure $3 \mathrm{~A}$ and $3 \mathrm{~B}) . \mathrm{AUC}_{5}$ and $\mathrm{AUC}_{15}$ values in FD patients were not also significantly $\left(\mathrm{p}=0.094, \mathrm{R}^{2}=0.156 ; \mathrm{p}=0.112, \mathrm{R}^{2}=0.142\right)$ associated with abdominal fullness (Figure $3 \mathrm{~A}$ and $3 \mathrm{~B}$ ). $\mathrm{AUC}_{5} / \mathrm{AUC}_{\mathrm{inf}}$ and $\mathrm{AUC}_{15} / \mathrm{AUC}_{\mathrm{inf}}$ values in FD patients were not also significantly $\left(\mathrm{p}=0.081, \mathrm{R}^{2}=0.168 ; \mathrm{p}=0.104\right.$,
$\mathrm{R}^{2}=0.148$ ) associated with abdominal fullness (Figure $3 \mathrm{C}$ and $3 \mathrm{D}$ ). In addition, $\mathrm{AUC}_{5} / \mathrm{AUC}_{\mathrm{inf}}$ and $\mathrm{AUC}_{15} / \mathrm{AUC}_{\text {inf }}$ values in healthy volunteers were not significantly $\left(\mathrm{p}=0.838, \mathrm{R}^{2}=0.002 ; \mathrm{p}=0.958, \mathrm{R}^{2}=0.0001\right)$ associated with abdominal fullness (Figure $3 \mathrm{C}$ and $3 \mathrm{D}$ ). We have also investigated the relationship between other clinical symptoms and AUC values in FD patients. There were no significant ( $p=0.19 ; \mathrm{p}=0.07$; $\mathrm{p}=0.139)$ relationship between $\mathrm{AUC}_{5}$ value and nausea, epigastralgia and abdominal discomfort in FD patients. In addition, there were no significant relationship between $\mathrm{AUC}_{15}$ value and nausea, epigastralgia and abdominal discomfort $(\mathrm{p}=0.04, \mathrm{p}=0.09 ; \mathrm{p}=0.123)$ in FD patients. Furthermore, the ratios of the disturbance of $\mathrm{T}_{\text {max }}$ and $\mathrm{T}_{1 / 2}$ values in $\mathrm{FD}$ patients were $33 \%(10 / 30)$ and $30 \%(9 / 30)$, respectively. The ratios of the disturbance of early phase of gastric emptying in FD patients were $23.3 \%(7 / 30)$ and $20 \%(6 / 30)$ for $\mathrm{AUC}_{5}$ and $\mathrm{AUC}_{15}$ values, respectively.

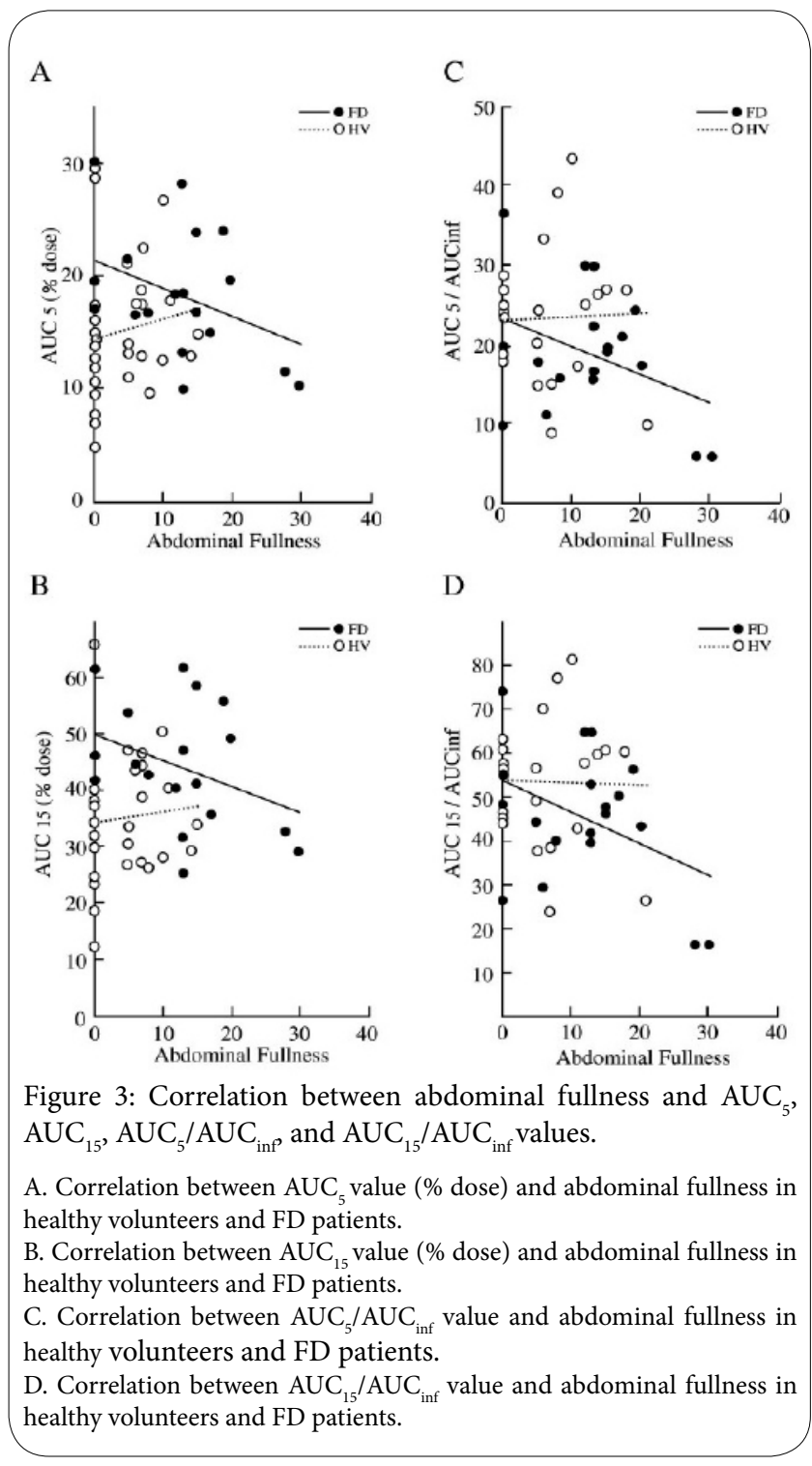

\section{Correlation between SRQ-D score and AUC values in FD patients}

There were no healthy volunteers with depression (SRQ-D score $>16$ ). In contrast, four patients were FD patients with depression. We could not find any significant differences in AUC and $\mathrm{T}_{\max }$ values between FD patients with depression and without it. There were significant 
Citation: Shimpuku M, Futagami S, Inamori M, Yamawaki H, Sato H, et al. (2014) Distinct Associations Between Depression Status and Initial Phase of Gastric Emptying in Functional Dyspepsia and Healthy Volunteers. Int J Gastroenterol Disord Ther 1: 107. DOI: http://dx.doi.org/10.15344/2393-8498/2014/106

correlations ( $\mathrm{p}=0.047, \mathrm{R}^{2}=0.134 ; \mathrm{p}=0.049, \mathrm{R}^{2}=0.131$ ) between $\mathrm{SRQ}-\mathrm{D}$ score and $\mathrm{AUC}_{5}$ and $\mathrm{AUC}_{15}$ values in healthy volunteers (Figure $4 \mathrm{~A}$ and $4 \mathrm{~B}$ ). In contrast, $\mathrm{AUC}_{5}$ and $\mathrm{AUC}_{15}$ values in $\mathrm{FD}$ patients were not significantly $\left(\mathrm{p}=0.608, \mathrm{R}^{2}=0.016 ; \mathrm{p}=0.672, \mathrm{R}^{2}=0.111\right)$ associated with SRQ-D score (Figure $4 \mathrm{~A}$ and $4 \mathrm{~B}$ ). There were significant correlations $\left(\mathrm{p}=0.048, \mathrm{R}^{2}=0.133 ; \mathrm{p}=0.047, \mathrm{R}^{2}=0.139\right)$ between SRQ-D score and $\mathrm{AUC}_{5} / \mathrm{AUC}_{\text {inf }}$ and $\mathrm{AUC}_{15} / \mathrm{AUC}_{\text {inf }}$ values in healthy volunteers (Figure $4 \mathrm{C}$ and $4 \mathrm{D})$. However, $\mathrm{AUC}_{5} / \mathrm{AUC}_{\text {inf }}$ and $\mathrm{AUC}_{15} / \mathrm{AUC}_{\text {inf }}$ values in $\mathrm{FD}$ patients were not significantly $\left(\mathrm{p}=0.702, \mathrm{R}^{2}=0.094 ; \mathrm{p}=0.798, \mathrm{R}^{2}=0.063\right)$ associated with SRQ-D score.

\section{Discussion}

In the ${ }^{13} \mathrm{C}$ acetate breath test, two popular parameters have been used to quantify gastric emptying rates, namely the time to the maximal excretion $\left(\mathrm{T}_{\max }\right)$ and the time to the half $\left({ }^{13} \mathrm{CO}_{2}\right)$ recovery $\mathrm{T}^{1 / 2}$. According to the conventional analysis of Ghoos et al. [31], $\mathrm{T}_{\max }$ value is determined based on a time-profile of the pulmonary $\left({ }^{13} \mathrm{CO}_{2}\right)$ excretion rate (\%dose/hr) and $\mathrm{T}_{1 / 2}$ value is based on that of the cumulative amount of $\left({ }^{13} \mathrm{CO}_{2}\right)$ recovered in the breath (\%dose). Although most studies evaluating gastric emptying in FD patients have reported delayed gastric emptying in a subset of patients, rapid gastric emptying has also been reported [20,21,32]. Sarnelli et al, found rapid gastric emptying for the solid and liquid components of a mixed meal in around 10\% [18]. Delgado-Aros et al have reported that rapid initial $1 \mathrm{hr}$ gastric emptying in $43 \%$ of FD patients, and associated gastric hypersensitivity with this type of emptying [33]. In this study, $\mathrm{AUC}_{15}$ value in $\mathrm{FD}$ patients was significantly greater compared to that in healthy volunteers. Therefore, it seems to be useful to estimate initial gastric emptying within 15 mins using $\mathrm{AUC}_{15}$ value or $\mathrm{AUC}_{15} / \mathrm{AUC}_{\text {inf }}$ as well as $\mathrm{T}_{\text {max }}$ value in $\mathrm{FD}$ patients. In addition to $T_{\max }$ value, it is very important for diagnosis of $\mathrm{FD}$ patients to evaluate initial gastric emptying in 15 mins postprandial phase. Previous studies have reported that rapid gastric emptying as well as delayed gastric emptying was also linked to functional dyspepsia [21,32]. Gastric emptying and duodenal glucose delivery are closely regulated $[27,28]$. Early phase of gastric emptying is usually $5-15 \mathrm{~min}$ in duration and is influenced by intragastric volume and associated with duodenal glucose delivery $[27,29,30]$. Lunding et al. have also reported that FD patients had significantly fast gastric emptying at $5 \mathrm{~min}$ compared to healthy volunteers [5]. Therefore, we also investigated $\mathrm{AUC}_{15}$ or $\mathrm{AUC}_{15} / \mathrm{AUC}_{\text {inf }}$ values as initial phase of gastric emptying within $15 \mathrm{~min}$ in this study. However, further studies will be needed to determine whether $\mathrm{AUC}_{15}$ or $\mathrm{AUC}_{15} / \mathrm{AUC}_{\text {inf }}$ actually reflected on early phase of gastric emptying in $\mathrm{FD}$ patients. Tack et al. have also reported thatapproximately $15 \mathrm{~min}$ are required for maximum gastric relaxation to occur after intake of a liquid test meal [4]. Lee et al have reported that gastric flow into the duodenum including gastric acid inhibits gastric accommodation to a meal [34]. In addition, in a scintigraphic study, early redistribution of the meal to the distal stomach or accelerated gastric emptying in the postprandial period was associated with symptoms of early satiety [35]. Considering previous reports, greater $\mathrm{AUC}_{5}$ and $\mathrm{AUC}_{15}$ values compared to healthy volunteers may be a pivotal factor for interaction between gastric accommodation and early phase of gastric flow into the duodenum.

Next, we compared initial gastric emptying within 15 mins with clinical symptoms in FD patients and healthy volunteers. However, there was no significant relationship between initial gastric emptying at $5 \mathrm{~min}$ and $15 \mathrm{~min}$ and abdominal fullness in both of FD patient and healthy volunteers. Most studies following the Rome II criteria have

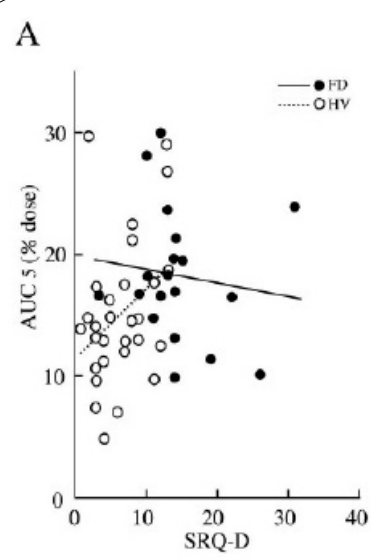

$\mathrm{C}$

B

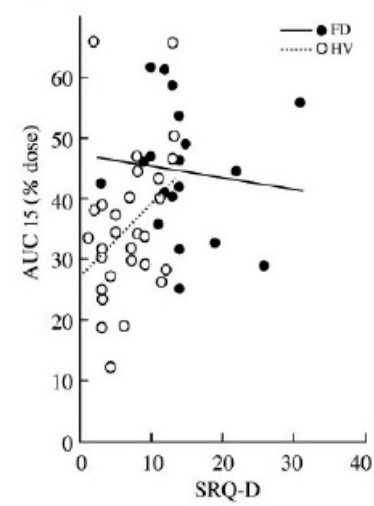

Figure 4: Correlation between SRQ-D score and $\mathrm{AUC}_{5}, \mathrm{AUC}_{15}$, $\mathrm{AUC}_{5} / \mathrm{AUC}_{\text {inf }}$ and $\mathrm{AUC}_{15} / \mathrm{AUC}_{\text {inf }}$ values.

A.Correlation between $\mathrm{AUC}_{5}$ value (\% dose) and SRQ-D score in healthy volunteers and FD patients.

B.Correlation between $\mathrm{AUC}_{15}$ value (\% dose) and SRQ-D score in healthy volunteers and FD patients.

C.Correlation between $\mathrm{AUC}_{5} / \mathrm{AUCi}_{\mathrm{nf}}$ value and SRQ-D score in healthy volunteers andFD patients.

D.Correlation between $\mathrm{AUC}_{15} / \mathrm{AUC}_{\text {inf }}$ value and SRQ-D score in healthy volunteersFD patients.

failed to find a good correlation between clinical symptoms and gastric emptying [36].We have first reported the association between abdominal fullness and initial gastric emptying within 15 mins in healthy volunteers and FD patients.

Studies have shown that the prevalence of psychological disorders is significantly higher in patients with FD than in the general population $[37,38]$. Lee et al have reported a significant correlation between clinical depression and FD [37]. We have also reported that SRQ-D scores in FD patients are relatively higher than that in healthy volunteers. In addition, previous studies have reported that psychogenic factors such as depression are associated with gastric emptying [13,14]. Then, Kusano et al have reported that early phase of gastric emptying plays important roles in FD patients as well as entire gastric emptying $[21,32]$. Considering these reports, it warrants further exploration to clarify the precise mechanisms underlying disturbed gastric emptying in initial postprandial phase within 15 mins and depressive status in FD patients. Therefore, we compared depressive state with early phase of gastric emptying in healthy volunteers and FD patients using 
Citation: Shimpuku M, Futagami S, Inamori M, Yamawaki H, Sato H, et al. (2014) Distinct Associations Between Depression Status and Initial Phase of Gastric Emptying in Functional Dyspepsia and Healthy Volunteers. Int J Gastroenterol Disord Ther 1: 106. DOI: http://dx.doi.org/10.15344/2393-8498/2014/106

SRQ-D score. However, there was no significant relationship between initial gastric emptying within 15 mins and depressive state in FD patients. Therefore, further studies will be needed to clarify whether psychological disorders such as depression can modulate initial and late phase of gastric emptying in healthy volunteers.

The present study has some limitations. In this study, we compared AUC values in FD patients with healthy volunteers in small sample size. Another limitation of this study was that the precise physiological mechanisms underlying disturbed gastric emptyng in initial postoprandial phase within 15 mins and depressive status in FD patients remains unclear. Taken together, impairment of initial gastric emptying within 15 mins may play critical roles in functional dyspepsia. Further studies will be needed to clarify whether $\mathrm{AUC}_{15}$ or $\mathrm{AUC}_{15} / \mathrm{AUC}_{\text {inf }}$ reflected on early phase of gastric emptying.

\section{Competing Interests}

The authors declare that they have no competing interests.

\section{Author's contribution}

Shimpuku M, Yamawaki H, Kodaka Y and Kawagoe T contributed substantially to data acquisition. Sato $\mathrm{H}$ contributed towards statistical analysis of the data and interpretation of results. Inamori M, Sakamoto C, Suzuki H and Saitow F cotributed towards direction of the study. Finally Shimpuku M, Futagami S and Gudis K worked with writing the manuscript.

\section{Funding}

This work was supported in part by grants from the Ministry of Education, Culture, and Science and from the Ministry of Health, Japan.

\section{References}

1. Tack J, Talley NJ, Camilleri M, Holtman G, Hu P, et al. (2006) Functional gastroduodenal disorders. Gastroenterology 130: 1466-1479.

2. Talley NJ, Zinsmeister AR, Schleck CD, Melton LJ 3rd. (1992) Dyspepsia and dyspepsia subgroups: a population-based study. Gastroenterology 102: $1259-1268$.

3. Castillo EJ, Camilleri M, Locke GR, Buon DD, Stephens DA, et al (2004) A community-based, controlled study of the epidemiology and pathophysiology of dyspepsia. Clin Gastroenterol Hepatol 2: 985-996.

4. Tack J, Piessevaux H, Coulie B, Caenepeel P, Janssens J (1998) Role of impaired gastric accommodation to a meal in functional dyspepsia. Gastroenterology 115: 1346-1352.

5. Lunding JA, Tefera S, Gilja OH, Hausken T, Bayati A, et al. (2006) Rapid initial gastric emptying and hypersensitivity to gastric filling in functiona dyspepsia: effects of duodenal lipids. Scand J Gastroenterol 41: 10281036.

6. Holtmann G, Goebell H, Talley J (1996) Impaired small intestinal peristaltic refluxes and sensory thresholds are independent functional disturbances in patients with chronic unexplained dyspepsia. Am J Gastroenterol 91: 485491.

7. Samsom M, Verhagen MA, vanBerge Henegouwen GP, Smout AJ (1999) Abnormal clearance of exogenous acid and increased acid sensitivity of the proximal duodenum in dyspeptic patients. Gastroenterology 116: 515-520.

8. Takahashi Y, Amano Y, Yuki T, Ose T, Miyake T, et al. (2006) Influence of acidsuppressants on gastric emptying: cross-over analysis in healthy volunteers. J Gastroenterol Hepatol 21: 1664-1668.

9. Shimpuku M, Futagami S, Kawagoe T, Nagoya H, Shindo T, et al. (2011) G-protein $\beta 3$ subunit $825 C C$ genotype is associated with postprandial distress syndrome with impaired gastric emptying and with the feeling of hunger in Japanese. Neurogastroenterol Motil 23: 1073-1080.
10. Holtmann G, Siffert W, Haag S, Mueller N, Langkafel M, et al. (2004) G-protein beta 3 subunit 825 CC genotype is associated with unexplained (functional) dyspepsia. Gastroenterology 126: 971-979.

11. Quigley EM (2002)Gastric motor and sensory function and motor disorders of the stomach. In: Feldman M, Friedman LS, Sleisenger MH, editors. Gastrointestinal and liver disease, pathophysiology/diagnosis/ management. Philadelphia: WB Sanders, pp 691-714.

12. Quigley EM ((2004)) Gastric emptying in functional gastrointestinal disorders. Aliment Pharmacol Ther 20: 56-60.

13. Quick C, Kliem A, Berger S, Hocke M, Tancer M, et al. (2010) Gastric dysmotility in major depression. Prog Neurosychopharmacol Biol Psychiatry 34: 92-97.

14. Ruhland C, Koschke M, Greiner W, Peupelmann J, Pietsch U, et al. (2008) Gastric dysmotility in patients with major depression. J Affect Disord 110: 185-190.

15. Shindo T, Futagami S, Hiratsuka T, Horie A, Hamamoto T, et al. (2009) Comparison of gastric emptying and plasma ghrelin levels in patients with functional dyspepsia and non-erosive reflux disease. Digestion 79: 65-72.

16. Futagami S, Iwakiri K, Shindo T, Kawagoe T, Horie A, et al. (2010) The prokinetic effect of mosapride citrate combined with omeprazole therapy improves clinical symptoms and gastric emptying in PPI-resistant NERD patients with delayed gastric emptying. J Gastroenterol 45: 413-421.

17. Futagami S, Shimpuku M, Song JM, Kodaka Y, Yamawaki H, et al. (2012) Nizatidine improves clinical symptoms and gastric emptying in patients with functional dyspepsia accompanied by impaired gastric emptying. Digestion 86: 114-121.

18. Sarnelli G, Caenepeel P, Geypens B, Janssens J, Tack J. (2003) Symptoms associated with impaired gastric emptying of solids and liquids in functional dyspepsia. Am J Gastroenterol 98: 783-788.

19. Stanghellini V, Tosetti C, Paternico A, Barbar G, Morsellini-Labate AM, et al. (1996) Risk indications of delayed gastric emptying of solids in patients with functional dyspepsia. Gastroenterology 110: 1036-1042.

20. Maes BD, Ghoos YF, Hiele MI, Rutgeerts PJ (1997) Gastric emptying rate of solids in patients with nonulcer dyspepsia. Dig Dis Sci 42: 1158-1162.

21. Kusano M, Zai H, Shimoyama $Y$, Hosaka H, Kuribayashi S, et al. (2011) Rapid gastric emptying, rather than delayed gastric emptying, rather than delayed gastric emptying, might provoke functional dyspepsia. J Gastroenterol Hepatol 26: 75-78.

22. Drossman DA (2006) The functional gastrointestinal disorders and the Rome III process. Gastroenterology 130: 1377-1390.

23. Portincasa P, Altomare DF, Moschetta A, Baldassarre G, Di Ciaula A, et al. (2000) The effect of acute oral erythromycin on gallbladder motility and on upper gastrointestinal symptoms in gastrectomized patients with and without gallstones: a randomized, placebo-controlled ultrasonographic study. Am J Gastroenterol 95: 3444-3451.

24. McColl K, Murray L, El-Omar E, Dickson A, El-Nujumi A, et al. (1998) Symptomatic benefit from eradicating Helicobacter pylori infection in patients with nonulcer dyspepsia. N Engl J Med 339: 1869-1874.

25. Rockliff BW (1969) A brief self-rating questionnaire for depression (SRQ-D). Psychosomatics 10: 236-243.

26. Hellmig S, Von Schöning F, Gadow C, Katsoulis S, Hedderich J, et al. (2006) Gastric emptying time of fluids and solids in healthy subjects determined by $13 \mathrm{C}$ breath tests: influence of age, sex and body mass index. J Gastroenterol Hepatol 21: 1832-1838.

27. Hunt JN, Smith JL, Jiang CL (1985) Effect of meal volume and energy density on the gastric emptying of carbohydrates. Gastroenterology 89: 1326-1330.

28. Lin HC, Doty JE, Reedy TJ, Meyer JH (1989) Inhibition of gastric emptying by glucose depends on length of intestine exposed to nutrient. Am J Physiol 256: G404-G411.

29. Brener W, Hendrix TR, McHugh PR. (2003) Regulation of the gastric emptying of glucose. Gastroenterology 85: 76-82.

30. Kaplan JM, Spector AC, Grill HJ (1992) Dynamics of gastric emptying during and after stomach fill. Am J Physiol 263: R813-R819. 
Citation: Shimpuku M, Futagami S, Inamori M, Yamawaki H, Sato H, et al. (2014) Distinct Associations Between Depression Status and Initial Phase of Gastric Emptying in Functional Dyspepsia and Healthy Volunteers. Int J Gastroenterol Disord Ther 1: 106. DOI: http://dx.doi.org/10.15344/2393-8498/2014/106

31. Ghoos YF, Maes BD, Geypens BJ, Mys G, Hiele MI, et al. (1993) Measurement of gastric emptying rate of solids by means of a carbonlabeled octanoic acid breath test. Gastroenterology 104: 1640-1647.

32. Zai H, Kusano M (2009) Investigation of gastric emptying disorders in patients with functional dyspepsia reveals impaired inhibitory gastric emptying regulation in the early postcibal period. Digestion 79: 13-18.

33. Delgado-Aros S, Camilleri M, Cremonini F, Ferber I, Stephens D, et al. (2004) Contributions of gastric volumes and gastric emptying to meal size and postmeal symptoms in functional dyspepsia. Gastroenterology 127 : 1685-1694.

34. Lee KJ, Vos R, Janssens J, Tack J. (2004) Influence of duodenal acidification on the sensorimotor function of the proximal stomach in humans. Am J Physiol Gastrointest Liver Physiol 286: G278-G284.

35. Piessevaux H, Tack J, Walrand S, Pauwels S, Geubel A (2003) Intragastric distribution of a standardized meal in health and functional dyspepsia: correlation with specific symptoms. Neurogastroenterol Motil 15: 447-455.

36. Tack J, Bisschops R, Sarnelli G (2004) Pathophysiology and treatment of functional dyspepsia. Gastroentelogy 127: 1239-1255.

37. Lee HJ, Lee SY, Kim JH, Sing IK, Park HS, et al. (2010) Depressive mood and quality of life in functional gastrointestinal disorders: differences between functional dyspepsia, irritable bowel syndrome and overlap syndrome. Gen Hosp Psychiatry 32: 499-502.

38. Haug TT, Svebak S, Wilhelmsen I, Berstad A, Ursin H (1994) Psychological factors and somatic symptoms in functional dyspepsia. A comparison with duodenal ulcer and healthy controls. J Psychosom Res 38: 281-91. 